\title{
A ASSOCIAÇÃO CONTRA A HIERARQUIA
}

* Fernando C. Prestes Motta

** Gustavo L. Campos Netto

As duplas possibilidades do tema alteridade para estudos organizacionais, à luz de vários autores.

The huge possibilities to the theme alterity to organizational studies through different authors.

\section{PALAVRAS-CHAVE:}

Alteridade, ação comunicativa, sistema, mundo da vida (Lebenswelt), sujeito competente.

\section{KEY WORDS:}

Alterity, communicative action, system, world of life (Lebenswelt), competent person.

\footnotetext{
* Professor Titular do Departamento de Administração Geral $\theta$ Recursos Humanos da EAESP/ FGV.

** Mestre em Administração de Empresas pela Pontifícia Universidade Católica de São Paulo.
}

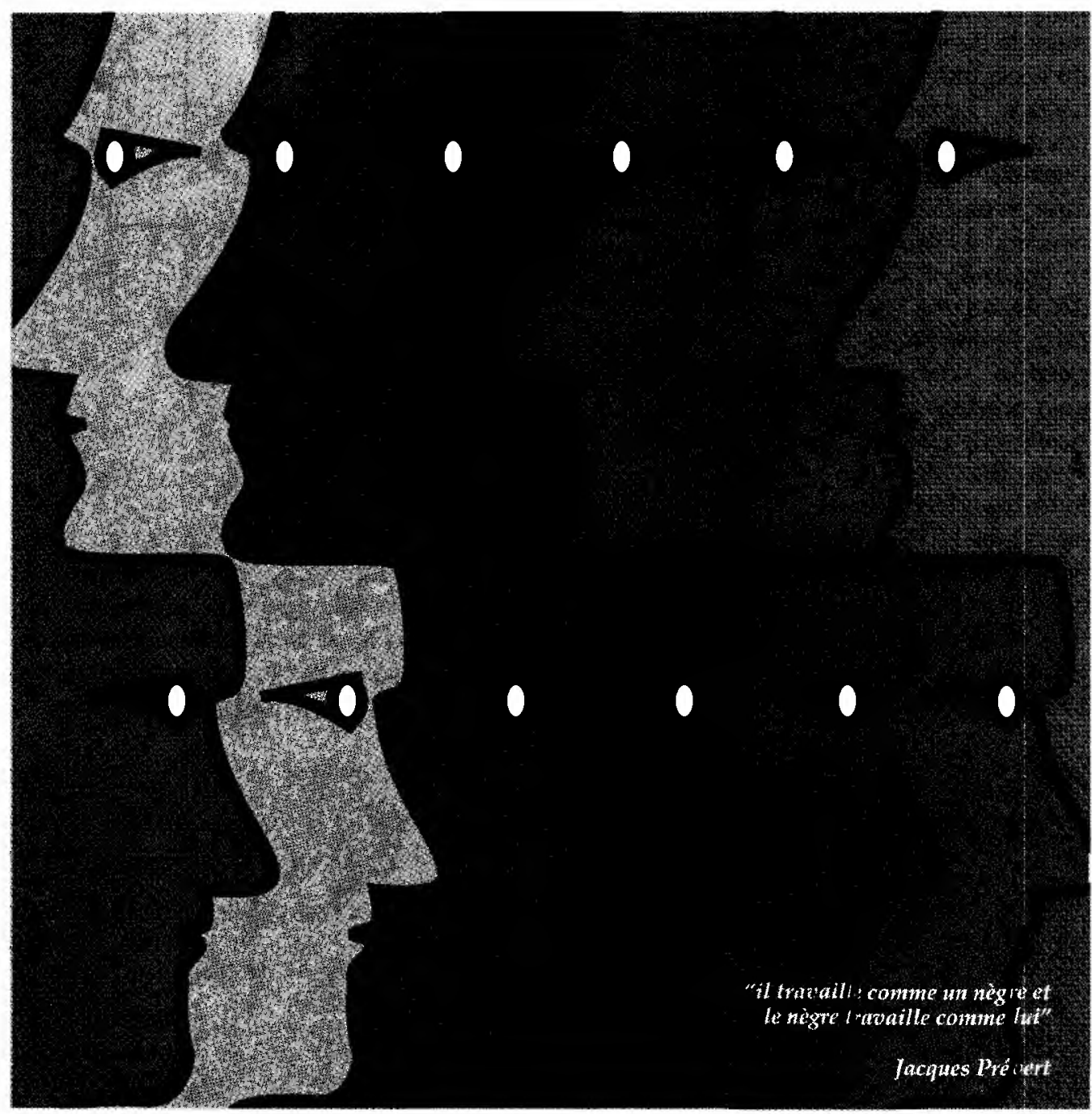


Talvez pareça um pouco estranha a ausência do tema Alteridade nos trabalhos mais importantes na área de estudos organizacionais. A ausência não se observa apenas nos estudos mais gerencialistas; ela também pode ser notada na maior parte dos trabalhos de caráter mais sociológico ou psicossociológico.

É com o interacionismo simbólico que essa questão irá merecer um lugar mais central nas análises desenvolvidas pelas Ciências Sociais, salvo, talvez, no caso da Antropologia, onde seu lugar parece mais consagrado. De resto, o interacionismo simbólico está bastante próximo do método antropológico.

Outras teorias sociológicas não são em si contrárias ao tratamento da questão da alteridade, mas podem tomar essa posição quando submetidas a uma objetivação e a uma formalização mais ideológicas, talvez até mais religiosas que científicas. Refiro-me, por exemplo, a certos usos do pensamento de Marx ${ }^{1}$, que, sendo burocráticos, escondem mais o problema que o esclarecem. Isto ocorre com a maior parte da literatura marxista-leninista e, certamente, stalinista.

Evidentemente, isto não é verdadeiro para um grande número de pensadores que sempre trabalharam de forma independente de partidos e sindicatos burocratizados da esquerda. Há muitos trabathos que procuram, mesmo, colocar a questão da alteridade no centro da discussão sobre a sociedade.

Se o tema está ausente de diversas tradições em Ciências Sociais, o mesmo não ocorre nos textos psicanalíticos de Freud, que trataram das questões ligadas a grupos, instituições e cultura. Todavia, esta é muito provavelmente a parte menos conhecida da psicanálise. De fato, para Freud o centro das questões que dizem respeito às Ciências Sociais é a noção da alteridade, termo, entretanto, que não utiliza.

No pensamento psicanalítico, a noção de alteridade se refere às modalidades específicas de que se revestem nossos contatos com outros seres. Tais modalidades implicam que aceitemos vê-los em suas singularidades, o que significa a não-aceitação dos outros seres enquanto instrumentos para nossa satisfação. $\mathrm{Da}$ mesma forma, a alteridade se refere tam- bém aos contatos que os outros seres estabelecem conosco, contatos nos quais aparecemos para eles em nossa singularidade. Tomar a alteridade como centro implica, portanto, o abandono das categorizações que agrupam indivíduos diferentes, encobrindo essas diferenças. Uma sociologia baseada na alteridade terá de dar conta da complexidade infinitamente maior de comportamentos que ocorrem entre seres que, sendo iguais em sua humanidade, serão necessariamente diversos.

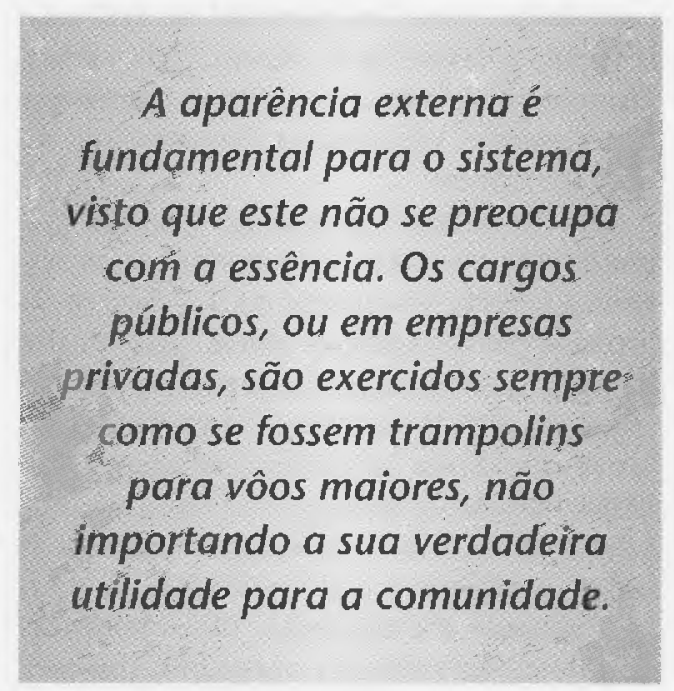

A questão da alteridade também esteve presente na história do pensamento filosófico. Entretanto, somente no século XX ela começa a ocupar um lugar importante no pensamento do Ocidente. E sobretudo no fim do século que a teoria da ação comunicativa de Jürgen Habermas ${ }^{2}$ e, de um certo ponto de vista, o pensamento de Michel Foucalt vāo fazer da alteridade o centro da dinâmica social. É preciso salientar que, evidentemente, outros filósofos trabalharam sobre essa questão, cabendo, aqui, referir-se a Martin Buber ${ }^{3}$, filósofo bastante religioso que parece haver construído uma ponte entre o Ocidente e o Oriente com sua visão cósmica, na qual budismo, taoísmo e hassidismo estão presentes. Ressalte-se $o$ antigo ensinamento, sobre o qual devemos pensar:

"Ninguém deve se enganar sobre essa questão do eu e do outro. Não há nada que não seja Buda, sem exceção."
1. MARX, Karl. A guerra civil na França. In: MARX, Karl; ENGELS, Friedrich. Textos. São Paulo: Edições Sociais, 1975.

2. HABERMAS, Jürgen. The theory or communicative action. London: Heinemann, 1984.

3. BUBER, Martin. Eu e tu. São Paulo: Cortez \& Moraes, 1979. 
A filosofia de Buber sublinhou a questão da unidade dos contrários. Ela se coloca como filosofia do diálogo e da relação. A existência real do eu depende de sua relação com o outro e a verdade somente pode ser encontrada entre verdades múltiplas. As contradições ou as oposições trazem, freqüentemente, a plenitude consigo. É preciso identificá-la entre os termos das contradições. A vida e a obra de Buber parecem obedecer a uma série de relações dialógicas, a ilustração mesma de uma filosofia da relação, uma filosofia do "entre", uma filosofia da ação concebida como inseparável da reflexão teórica - Feuerbach, Kant, Nietzsche, Simmel, Rozenzweig e Gustav Landauer são algumas influências importantes na obra de Buber.

Há em Buber um esboço de uma antropologia das relações inter-humanas - e nela a relação é o essencial. De fato, o filosófico compreende o "entre" como uma categoria primordial, a palavra dando conta do ser do homem. E através da palavra que o ser se realiza enquanto tal. Dessa forma, o diálogo é o fundamento ontológico do inter-humano. A relação é o fato primitivo e a reciprocidade, a ação que permite a totalização. $\mathrm{O}$ eu pode assumir várias atitudes ante uma relação. Há duas que chamam a atenção de Buber: as denominadas atitude "eu e você" e atitude "eu e isto". A primeira é o encontro dos parceiros na reciprocidade; é a atitude que possibilita a confirmação mútua do eu e do tu enquanto seres humanos. A segunda é a utilização, a objetivação, que só pode se exprimir como submissão e, portanto, como dominação. É por essa razão que se pode dizer que o "isto" vem depois do "você".

$\mathrm{O}$ "eu" da primeira atitude não é o mesmo "eu" da segunda. A palavra, no caso da relação "eu e você", tem por objetivo a existência e, por essa razão, ela não é utilitária. No segundo caso - "eu e isto" -, a palavra tem por objetivo conhecer, impor, ordenar, estruturar e transformar. E é possível escolher tanto o universo da primeira como o da segunda. É verdade que são universos diferentes, mas não é menos verdadeiro que essas atitudes precisam ser conversíveis e reversíveis, de acordo com a decisão humana e segundo a relação entre o "eu" e o mundo.
Essa concepção parece estar de acordo com o que também Merleau-Ponty colocou, ao considerar a consciência como uma rede de intenções significáveis. Para ele, o sujeito é a abertura ao outro. Não há "eu" sem "isto". O "você" abre a possibilidade do encontro e o "eu" decide encontrá-lo. Nos termos colocados por Buber, eu me torno "eu" na relação com o "você". É Buber quem diz:

\section{"Se o homem não pode viver sem o 'isto', não podemos esquecer que aquele que vive somente em relação ao 'isto' não é um homem".}

Essas idéias permitem a Buber a descrição da comunidade como alguma coisa que depende dos membros, enquanto unidos entre si por relações vivas e mútuas que podem nascer apenas quando existe sentimento. Não se pode dizer que a burocracia, a metaburocracia e outras "cracias" possam ser vistas em termos semelhantes. É a descrição de uma verdadeira comunidade que pode ser imaginada em algumas, e certamente não em todas, definições de federação ou, mais simplesmente, de associação.

$\mathrm{Na}$ teoria da ação comunicativa de Jürgen Habermas há outras formas de chegar a isto, ou seja, à questão da alteridade. A discussão já antiga, mas sempre muito importante, da racionalidade, levada a cabo por filósofos da Escola de Frankfurt, é retomada por Habermas, que introduz a questão da ação comunicativa. É fundamental a discussão que ele faz entre "sistema" e "mundo de vida". O primeiro é o mundo da regra, domínio do Direito, da Administração e da Economia, enquanto o segundo é o local no qual a reciprocidade se realiza ao nível do indivíduo, dos grupos, das coletividades, das sociedades e da cultura.

"Sistema" e "mundo de vida", eles próprios, mantêm relações entre si, e essas relações ameaçam atualmente a maior parte dos seres vivos na Terra. Isto acontece porque há uma "colonização do mundo de vida" pelo "sistema". Quer dizer que é preciso que relações sociais igualitárias, livres e responsáveis comecem a obrigar o sistema a retornar a seu lugar e papel na dialética das sociedades. É impossível aqui não lembrar da impor- 
tância atribuída às relações formais e informais por vários livros, hoje clássicos, na área de análise organizacional. No quadro de uma sociologia de inspiração parsoniana, Etzioni ${ }^{4}$, por exemplo, insistiu muito sobre a relação formal-informal. Outros, como Blau e Scott ${ }^{5}$, March e Simon $^{6}$, sublinharam a mesma questão. $\mathrm{O}$ mais interessante, entretanto, é constatar uma proximidade das idéias de Habermas com certas análises marxistas mais ou menos recentes, que são por vezes chamadas autonomistas. Penso nos trabalhos de Bernardo ${ }^{7}$, Negri $^{8}$ e Tronti, entre outros, que insistem na forma de transformação das relaçōes sociais novas.

Habermas construiu a sua teoria tentando mostrar que as patologias da modernização não atingiram a totalidade do ambiente humano. E em função disto que se abre a possibilidade de uma reversão, ampliando-se a açăo comunicativa voltada a valores, que deixaria a racionalidade instrumental apenas nas áreas que lhe são realmente competentes. Este conceito de Habermas também é fundamental para a compreensão de sua teoria. Consiste em identificar quais as áreas de vivência humana que foram totalmente colonizadas pela razão instrumental, e aquelas em que esta ainda não penetrou totalmente e nas quais a ação comunicativa existe e é praticada com sucesso. Habermas observou que a modemização da sociedade dividiu o ambiente humano em dois grandes setores. O primeiro é o setor externo, composto pelas grandes instituiçôes dominadoras modernas. Estas se impõem, de uma forma avassaladora, sobre a personalidade humana. Habermas denominou este primeiro setor de sistema, conceito que advém da própria Teoria de Sistemas. O sistema é composto estruturalmente pelo Estado burocrático e forte, e, portanto, pela luta pelo poder que se desenvolve na socieda de e também pela empresa capitalista e, por conseguinte, por toda a luta por dinheiro que se desenvolve na sociedade. Sistema, sucintamente, pode ser entendido por poder e dinheiro. São áreas que são realmente dominadas por uma racionalidade voltada apenas para os fins (instrumental) e com um posicionamento ético e moral muitas vezes questionável. $\mathrm{O}$ sistema é formado por todas as institui

ções sociais que foram dominadas por um pensar e um agir racional, competitivo, ansioso por vantagens quantificáveis ou pelo poder egoístico. A aparência externa é fundamental para o sistema, visto que este não se preocupa com a essência. Os cargos públicos, ou em empresas privadas, são exercidos sempre como se fossem trampolins para vôos maiores, não importando a sua verdadeira utilidade para a comunidade. Enfim, a razão instrumental reina absoluta.

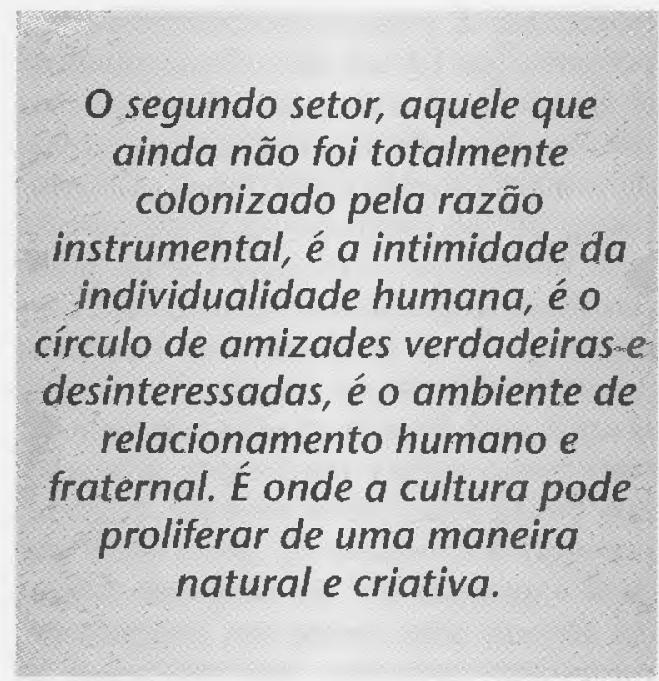

U segundo setor, aquele que ainda não foi totalmente colonizado pela razão instrumental, é a intimidade da individualidade humana, é o círculo de amizades verdadeiras e desinteressadas, é o ambiente de relacionamento humano e fraternal. $\hat{\mathrm{E}}$ onde a cultura pode proliferar de uma maneira natural e criativa. Em suma, é onde predomina o diálogo livre de coação e de manipulação, onde a argumentação sincera sempre reina. É só neste tipo de ambiente que a ação comunicativa pode ocorrer. Este setor, Habermas denominou de mundo da vida (Lebenswelt). Os componentes estruturais do mundo da vida são a cultura, a personalidade e a sociedade. A cultura está incluída, à medida que provoque um conhecimento suscetível do consenso, ou seja, um saber verdadeiramente válido, porque esgotou todas as suas possibilidades. A sociedade deve ser vista aqui como interações legitimamente reguladas, que são fundamentais para a existência saudável do ser humano. Por último, a personalidade é importantíssima, pois só no mun-
4. ETZIONI, Amitai. Modern organizations. Englewood Cliff: Prentice-Hall, 1964.

5. BLAU, Peter, SCOTT, W. Richard. Formal organizations. San Francisco: Chandler, 1962.

6. MARCH, J.G., SIMON, H.A. Organizations. New York: John Wiley, 1958

7. BERNARDO, João. Marx crítico de Marx. Porto: Edições Afrontamento, 1977. $3 \mathrm{v}$.

8. NEGRI, Antonio. La classe ouvriere contre l'état. Paris: Galilée, 1978. 
9. GUATARI, Felix. Revolução Molecular: pulsações politicas do desejo. São Paulo, Brasiliense, 1987.

10. DELEUZE, Gilles. Capitalisme et schizopheénie: mille plateaux. Paris: Minuit, 1980.

11. PROUDHON, Pierre-Joseph. Du principe fédératif. Paris: Marcel Rivière et Cie, 1959

12. BERGER, Claude. Marx l'Association, l'anti-Lenine. Paris: Payot, 1974

13. ORTIZ, Renato. Cultura brasileira e identidade nacional. São Paulo: Brasiliense, 1985. do da vida é que ela encontra um ambiente para o seu natural e equilibrado desenvolvimento, sempre em interação desinteressada com outros.

É no mundo da vida, portanto, que Habermas acredita estarem os potenciais inabaláveis da razão humana, que podem sobreviver à colonização pela razão instrumental e revertê-la a ponto de esta predominar apenas dentro das áreas de sua competência, uma vez que até mesmo o próprio mundo da vida vem sendo, em muitas áreas, contaminado pela razão instrumental. É importante compreender, portanto, que há um claro desacoplamento do mundo da vida com o sistema. $O$ indivíduo deve adotar referências e padrões de comportamento diferentes, a cada momento de seu cotidiano. Quando transita pelo mundo da vida, no entanto, pode sentir-se mais relaxado, pois a espontaneidade é a mãe da sinceridade e esta não possui limitações no mundo da vida. Já quando está lidando no Sistema, tem de estar preocupado o tempo todo com uma luta pouco ética. Neste sentido, chega-se, portanto, à conclusão de que a modernidade é marcada por um momento delicado. De um lado, temos um sistema corrompido e castrador, que extermina as possibilidades da história da humanidade, recolocando-a nas trevas medievais (o que provocou o pessimismo de Adorno). De outro, existe o mundo da vida guardando toda a riqueza mais pura da natureza humana, que, no entanto, também já vem sendo contaminado pela razão instrumental. A figura 1 procura explicar melhor esta situação.

A ação comunicativa de Habermas, por enquanto predominante no mundo da vi$\mathrm{da}$, da forma como é proposta, cria novas perspectivas à medida que renova as possibilidades de resgate da razão humana com bases em ideais iluministas e pode ser vista como um instrumento importante para uma revalorização da ética atual.

Dito de outra forma, o mundo social apresenta dois grandes tipos de organização fundados sobre dois tipos diferentes de relações, que também se relacionam de formas diversas. Félix Guattari ${ }^{9}$ e Gilles Deleuze $^{10}$ falaram de árvore e rhizoma, imagens que nos podem auxiliar a pensar o social, bem como seu conhecimento; a árvore representando o princípio da centrali- zação hierárquica e o rhizoma, o princípio da federação; visão nova que atualiza a oposição Império Industrial e Anarquia Positiva ou Democracia Industrial, na obra de Pierre Joseph Proudhon ${ }^{11}$, no século XIX. Eros e Tânatos, Princípio do Prazer e Princípio da Realidade, vida e morte, diferença e repetição, rhizoma e árvore, sistema e mundo da vida constituem séries de oposições que parecem significar um conflito muito forte e difundido entre burocracia e associação, entre a relação da dominação e submissão de um lado e a cooperação livre do outro, entre hierarquia e federação, conflito, aliás, que Claude Berger $^{12}$ viu no marxismo-leninismo e cuja solução estaria num retorno a Marx, sem Lenin. Outros pensadores, porém, falaram de uma contradição que estaria presente na própria obra de Marx e que, longe de a empobrecer, a enriquece, uma vez que, a partir de uma visão dialética, a contradição é a fonte do desenvolvimento.

As contradições ou oposições são antigas na Filosofia ocidental e também no pensamento oriental. Elas estão ainda presentes numa grande parte das Ciências Sociais, compreendidas a Sociologia, a Ciência Política e a Antropologia, tornando-se a própria base da análise organizacional.

E preciso, pois, compreender que a forma federativa de organização, isto é, a associação, supõe uma forte coordenação e também a ausência de hierarquia. Por sua vez, a forma burocrática - e todas as suas variações contemporâneas - exige uma forte hierarquia, baseada no princípio da autoridade formal e no domínio da regra. A relação "eu e você" está na base do primeiro caso, enquanto a relação "eu e isto" está na base do segundo. A ação comunicativa é possível no primeiro caso, não o sendo no segundo.

É por isso que a identidade organizacional é, no caso de uma burocracia, uma identidade construída, que tem por objetivo a integração dos diversos grupos presentes. Sua existência é necessariamente política, tendo por função manter a organização em sua totalidade. É preciso, pois, perguntar sobre as pessoas que fazem a mediação entre o singular e o global, e é igualmente preciso saber a quem essa identidade organizacional beneficia.

Um trabalho interessante sobre esse assunto foi desenvolvido por Renato Ortiz ${ }^{13}$. 
Perguntando-se sobre as relações entre a cultura brasileira e a identidade nacional, ele começa, de forma sugestiva, pela citação de uma análise da religião nagô, de origem africana, feita por Elbein e Santos. Segundo Ortiz, a religião nagô parece ter desempenhado um papel importante na geração de valores no Brasil, e a citação que ele escolheu fala da palavra axé, bem conhecida hoje de boa parte da população, devido aos movimentos sociais negros $\mathrm{e}$ de comunicação de massa, sobretudo da televisão e do rádio. Axé é uma palavra que aproximadamente significa "salve", enquanto forma de cumprimento. $\mathrm{O}$ que importa perceber aqui é que essa palavra deve ser comunicada de uma pessoa a outra, numa relação direta, face a face. Somente dessa forma, de modo direto, se acredita que a força sagrada pode ser transmitida. Isto quer dizer que o "entre" pode manifestar-se totalmente, e o "eu" pode, dessa forma, tornar-se ser humano.

Estudando a cultura brasileira de uma perspectiva global, Roberto DaMatta ${ }^{14}$ tenta compreender a diferença entre "indivíduo" e "pessoa" no cotidiano dos brasileiros. Como cidadãos, os brasileiros amam seus direitos e sabem que é preciso cumprir seus deveres. Por essa razão, de modo geral, eles querem viver segundo as leis do País e segundo as regras das organizações das quais participam. Dito de outra forma, como outros povos do mundo, eles têm direitos e deveres que foram estabelecidos para todos. Entretanto, constitui um fato bastante conhecido que quase ninguém, nos estratos médios e altos da sociedade, deixa de utilizar os serviços do despachante, profissional que tem por função "agili-

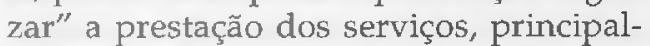
mente públicos, para essas pessoas. Só a existência desses intermediários demonstra a desigualdade social diante do Estado. Há também uma frase muito conhecida no Brasil; trata-se da seguinte pergunta: "Você sabe com quem está falando?". Ela é sempre pronunciada como ameaça, mas geralmente não produz grande efeito, porque, no fundo, todas as pessoas se julgam mais importantes que as demais.

O famoso "jeitinho", bem conhecido de brasileiros e estrangeiros que estão ou estiveram no Brasil, constitui-se também numa forma de personalização das relações sociais, com o objetivo de obter condições

\section{Figura 1}

\section{Colonização pela Razão Instrumental}

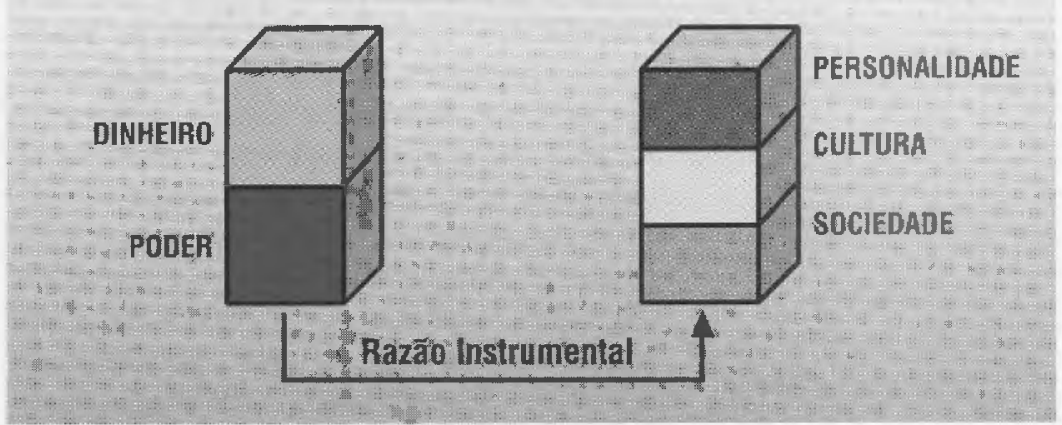

mais favoráveis para as demandas de alguém, de um grupo ou de uma instituição. Há muitas formas de "jeitinho", e não há necessariamente coincidência entre "jeitinho" e suborno. De qualquer forma, o uso do mecanismo exige qualidades de percepção nem sempre comuns.

As ilustrações desses casos brasileiros ajudam a introduzir o tema alteridade, colocando algumas tensões e dificuldades que estão no centro das questões que interessam a muitos analistas organizacionais, sejam eles antropólogos, psicólogos, sociólogos ou cientistas políticos: as questões ligadas à horizontalização das relações sociais nas organizações.

É muito difícil de se imaginar que as organizações modernas venham a se dispor a implementar uma mudança de paradigma tão drástica. A mudança não se dará em um espaço curto de tempo. Trata-se, ao contrário, de um processo lento, que deverá ocorrer através de um constante incentivo a mudanças de atitude como conseqüência natural de um ambiente saudável. O processo de mudança deverá ter uma evolução tal, que só ao final do mesmo, através de uma visão retrospectiva, é que se poderá dar conta da quantidade e da qualidade das transformações. Sendo feito desta forma, ele não representará, a curto prazo, uma grande ruptura que poderia ser perigosa até mesmo à própria sobrevivência da organização - e portanto poderia ser mais facilmente aceito pelos envolvidos na mudança. É importante atentar ao fato de que este processo não deve ser tomado como algo restrito às organizações, uma vez que certamente envolve transformações também a nível individual e social que estarão ocor-
14. DaMATTA, Roberto. Carnavais, malandros e heróis. Rio de Janeiro: Zahar, 1981. 
rendo simultaneamente, o que com certeza o torna muito mais complexo.

Com relação aos agentes da mudança, é muito importante que se perceba que inevitavelmente só poderão se tratar de Sujeitos Competentes. É fácil de se compreender isso, pois somente o Sujeito Competente, pela sua própria definição, obteve uma completa compreensão do verdadeiro intuito da mudança e mais ainda, uma verdadeira compreensão dos instrumentos disponíveis para a implementação desta transformação. Não se trata aqui, de qualquer tipo de preconceito ou elitização, mas sim da constatação de uma verdade natural: se alguém compreende sinceramente os grandes males causados pelo domínio da razão instrumental, compreende a necessidade urgente de seu combate, e também procura desenvolver os instrumentos disponíveis para realizar essa transformação de uma maneira harmônica; este indivíduo já é um Sujeito Competente. Ou seja, essa mudança jamais poderá ser implementada por indivíduos que não tenham atingido o pleno desenvolvimento cognitivo, o pleno desenvolvimento da capacidade de julgamento moral e que não estejam em equilíbrio, do ponto de vista psicológico, pois, caso contrário, não se trataria de uma verdadeira transformação, mas mais um sofisma, carregado de alienação e ideologia, destinado a se obter um determinado fim através do uso das pessoas e, portanto, continuando a ferir os princípios kantianos. $\mathrm{O}$ agente competente, por seu turno, estará agindo sempre em compromisso com a verdade, com a justiça e com a autenticidade, o que o colocaria necessariamente no âmbito da ação comunicativa.

Segundo Felix Guattari ${ }^{15}$, a cultura de massa produz indivíduos normalizados, articulados segundo determinados sistemas de valores e de submissão muitas vezes não explícitos, que produzem uma angústia e uma culpabilidade inconscientes. Para romper esta subjetividade de massa, Guattari propõe a idéia de se desenvolver modos de subjetivação singulares, "aquilo que poderíamos chamar de processos de singularização: uma maneira de recusar todos esses modos de encodificação preestabelecidos, todos esses modos de manipulação e de telecomando, recusá-los para construir, de certa forma, modos de sensibilidade, modos de relação com o de que produzam uma subjetividade singular. Uma singularização existencial que coincida com o desejo, com um gosto de viver, com uma vontade de construir um mundo no qual nos encontramos, com a instauração de dispositivos para mudar os tipos de sociedade, os tipos de valores que não são os nossos... Tais mutações da subjetividade não funcionam apenas no registro das ideologias, mas no próprio coração dos individuos, em sua maneira de perceber o mundo, de se articular como tecido urbano, com os processos maquínicos de trabalho, com a ordem social suporte dessas forças produtivas. $E$ se isso é verdade, não é utópico considerar que uma revolução, uma mudança social em nivel macropolítico, macrossocial, diz respeito também à questão da produção de subjetividade, o que deverá ser levado em conta pelos movimentos de emancipação".

Portanto, é fundamental ter em conta que uma micropolítica de transformação molecular, necessariamente deverá considerar um questionamento radical do conceito de indivíduo em direção à sua singularização. Tal questionamento deverá ser direcionado a romper o senso comum e criar espaço para o desenvolvimento das singularidades pessoais de uma maneira livre de qualquer tipo de imposição. Trata-se de criar a possibilidade de uma psicogênese que permita o desenvolvimento de todas as infinitas alternativas individuais. Para Guattari, o indivíduo se encontra em uma encruzilhada de múltiplos componentes de subjetividade e, portanto, direcioná-lo a um rumo libertador é o ponto que certamente resultará em um grande impulso às transformações. A ordem atual produz modos de relações humanas até em suas representações inconscientes; é necessário romper este processo e reorientá-lo a produções realmente autênticas. No caso brasileiro, o aspecto pessoalista e hierarquizante da sociedade é mais uma barreira.

Do ponto de vista social, Guattari faz outras relevantes considerações dentre as quais algumas nos seriam particularmente interessantes. As transformações sociais, tal como propostas aqui, tratam-se, na verdade, da implementação de um processo de mudança, e portanto a capacidade de articulação desse processo por parte dos agentes será fundamental para o seu sucesso. Trata-se da provocação de uma revolução, no sentido de se implantar uma 
realidade social que tenha como característica natural a impossibilidade de um retorno aos padrões anteriores. Nesse sentido, 0 exemplo de movimentos de minorias (ecológicos, raciais, étnicos, sexuais etc.), tanto em seus sucessos como fracassos, podem ser de grande valia. $O$ fato de no plano macro, movimentos desse tipo estarem conseguindo grande impacto, não garante o seu sucesso. É fundamental que internamente estejam bem articulados e definidos, pois é comum encontrar estruturas extremamente conservadoras, reacionárias no interior desses movimentos, o que nos remete à identificação clara dos agentes passiveis de implementar a articulação desse processo de mudanças à qual já nos referimos anteriormente. Essa contaminação interior dos movimentos sociais costuma ocorrer justamente em função de uma não substituição prévia (como frisamos anteriormente ser fundamental) do processo de subjetivação individual normalizador dos indivíduos por um processo de subjetivação singularizador. Por outro lado, esse inimigo interno se torna difícil de se identificar se comparado ao inimigo externo, muito bem definido logo na origem desses movimentos. Sendo de difícil identificação, esse inimigo interno é um grande agente do fracasso de alguns movimentos sociais.

A habilidade para captar e conectar desejos é sem dúvida outro ponto importante na articulação de movimentos de transformação. Isso permite agrupar agentes alinhados e compromissados com a transformação. Em um segundo momento, esta capacidade possibilita atender de pronto as aspirações do grupo social que se pretende atingir. $\mathrm{O}$ início da criação de uma organização baseada na alteridade não poderia deixar de ser uma transformação do ambiente organizacional, de tal forma que este se tornasse propício ao desenvolvimento do Sujeito Competente. Para isso é fundamental que se volte os olhos também para as constatações a que chegaram Piaget $\mathrm{e}$ Kohlberg. Segundo as constatações destes cientistas, existem certos fatores que impedem o completo desenvolvimento da capacidade cognitiva e de julgamento moral, e outros que são fundamentais para que isso possa acontecer. É importante que tais fatores sejam conhecidos, e que baseado neles se crie o ambiente propício ao desen- volvimento do Sujeito Competente. Somente através da proliferação do Sujeito Competente é que se poderá implantar e fazer sobreviver um ambiente baseado na interação de singularidades.

Dentre os pontos necessários à criação deste ambiente favorável ao Sujeito Competente, que se pode extrair dos trabalhos de Piaget e Kohlberg, pode-se destacar como principais:

- o bom nível de relacionamento interpessoal para Piaget e

- um comportamento orientado pela fundamentação das normas para Kohlberg.

Esses são pontos fundamentais para se atingir o último estágio do desenvolvimento cognitivo (Piaget) e o último estágio do desenvolvimento do julgamento moral (Kohlberg).

Portanto, é fundamental que se estimule dentro do ambiente organizacional um tipo de relacionamento interpessoal que transmita segurança aos indivíduos, no sentido de que se sintam à vontade para serem eles mesmos, para que não se preocupem com possíveis erros, para que haja uma confiança mútua, no sentido de que todos são considerados primeiramente pessoas completas, dignas e sinceras, independentemente das diversidades das características individuais e das qualidades profissionais ou de formação. Ou seja, é necessário que as pessoas se sintam confortáveis para serem dentro da empresa exatamente o que elas mesmas são. Esta segurança propiciaria uma alta qualidade de inter-relacionamentos de singularidades, permitindo ao indivíduo uma psicogênese favorável ao seu desenvolvimento cognitivo e assim alcançar um estágio que lhe possibilite realizar as mais complexas abstrações intelectuais, o que sem dúvida será também favorável para a organização. Além disso, um profissional neste estágio de desenvolvimento cognitivo aprenderá com muito mais facilidade a usar novas ferramentas de trabalho, criará outras tantas e poderá desenvolver formas mais criativas de trabalho. É fundamental a disseminação da idéia de que as pessoas sempre serão respeitadas exatamente como elas são em qualquer tipo de situação, e que elas podem ser necessárias à organização tam- 
bém em qualquer situação. Porém, para que se possa disseminar este ambiente, não há outra forma senão a ação baseada na sinceridade, na transparência das tomadas de decisões, e fundamentalmente na justiça interna (que, lembre-se, sāo também pressupostos da Ação Comunicativa). Note-se, ainda, que tais pontos pressupõem também um alto grau de descentralização administrativa, sem a qual tal ambiente não poderia ser implementado.

Porém, vale lembrar que não se trata apenas de uma alta qualidade de relação entre organização e funcionários, o que seria relativamente fácil de se atingir; trata-se de desenvolver e manter uma alta qualidade de relações interpessoais dentro da organização. Mais do que isso, que essas boas relações interpessoais sejam naturais e não uma tarefa a mais para os funcionários. Por isso mesmo, os pontos básicos citados acima precisariam ser amplamente disseminados.

O segundo ponto, relacionado às constatações de Kohlberg, significa incentivar um comportamento orientado pela fundamentação das normas. Ou seja, não é interessante ter indivíduos autômatos que se comportem de acordo com as normas, simplesmente porque elas foram escritas por alguém, em algum dia. É importante, para a organizaçäo, trabalhar com profissionais que saibam exatamente as razões fundamentais de todas as normas, assim como a explicação para os principais fatos pelos quais ele estiver passando. Isto faria com que os indivíduos trabalhassem baseados no bom sen- so e se libertassem da dominação da burocracia. O bom senso deve ser o guia para se saber se uma norma pode ou não ser desrespeitada em determinada situação. Isso sem dúvida traria muita economia para qualquer empresa, não só em. controles, mas também em termos de agilidade e simplificação de rotinas, porém com alto grau de honestidade e confiança em seus funcionários. Mas o mais importante é que se estaria contribuindo para a formação do Sujeito Competente capaz de fazer o mais complexo julgamento moral dentro de parâmetros justos.

Estes pontos citados acima, logicamente não têm a pretensão de estabelecer critérios rígidos para a implementação de uma mudança do atual paradigma organizacional ou das teorizações clássicas a esse respeito, mas são constatações que seguramente podem contribuir consideravelmente para nortear a formulação das referências iniciais de um processo de libertação das organizações. Seria importante também que, após a criação deste ambiente favorável ao desenvolvimento do Sujeito Competente, os princípios da ação comunicativa (verdade, justiça e autenticidade) estivessem sempre presentes, e embora eles sejam inerentes ao Sujeito Competente, a lembrança destes princípios seria uma forma de defesa das liberdades e direitos já então conquistados.

- Esse trabalho é a ampliação e o desenvolvimento do artigo de Fernando C. Prestes Motta, Aiteridade e Organização: A Associaçâo Contra a Hierarquia, ldéias, São Pau10. Fundação para o Desenvolvimento da Educaçāo, Série Idéias, 12, 1992

\section{BIBLIOGRAFIA SUPLEMENTAR}

* BRUNO, Lícia, o que é autonamismo. Sẩo Paulo: Brasilienșe, 1988 (Col. Primeiros Passos.)

* CHANLAT, Jean-François. L'individu dans l'arganization, les dimensions obliées. Quebec: Les Presses de L'Université de Laval, Éditions Eska, 1990.

* CLASTRES, Plerre. La Societé contre létat, recherches danthropalogie politique. Paris: Les Éditions de Minuit, 1974

* DELEUZE, G. La Difference et la répétition. Paris: Presses Universitaires de France, 1985.
* LAPLANTINE, Francois. Aprender antropología São Paulo: Brasiliense, 1989.

* MANDEL, Ernst. A teoria leninista da organizaçăo. Lisboa: Antidoto 1975.

* MEZAN, Renato. Freud oensador da cultura. São Paulo: Brasiliense, 1986 .

* _. Organizacão e poder:

* MNTZBERG, H. on management - inside our strange world or organizations. The Free Press, 1989.
Paulo: Atlas, 1986

MORGAN, Gareth. Images or or ganizations. Newbury Park, CA Sage Publications, 1989

* MOTIA, Fernando C. Prestes. Burocracia e autogestāo: a proposta de Proudhon. São Paulo: Brasiliense, 1981.

* PETERS, Thomas J., WATERMAN Ji, $H$. In search or excellence. New York: AcGraw- Hill, 1969.
* TRAGTENBERG, Maurício. Burocracia e ideologia. São Paulo: Ática, 1974.

$\%$ Reflexōes sobre 0 socialismo. São Paulo: Moderna, 1986

* WEBER, Max, Economia y sociedad. México: Fonda de Cultura Economica, 1969, $2 \mathrm{~V}$.

* Parlamentarismo e governo numa Alemanha reconstruida. Os pensadores. São Pau10: Ed. Abril, 1974. 